\title{
Sexually Transmitted Disease Screening
}

National Cancer Institute

\section{Source}

National Cancer Institute. Sexually Transmitted Disease Screening. NCI Thesaurus. Code C92878.

A test to detect the presence of a sexually transmissible disease such as HIV, chlamydia, syphilis, gonorrhea, hepatitis B or hepatitis C. 